\title{
Erratum zu: Big Data-Effekte auf digitale Protestakteure
}

\section{Erratum zu:}

\section{Kapitel 8 in: E. Mülling, Big Data und der digitale Ungehorsam, Bürgergesellschaft und Demokratie, https://doi.org/10.1007/978-3-658-24159-9_8}

Folgende Angaben zu der Person Enno Lenze waren auf S.193 der Publikation „Bürgergesellschaft und Demokratie - Big Data und der digitale Ungehorsam“ von Eric Mülling falsch: „Enno Lenze verdient seinen Lebensunterhalt als Museumsleiter in Berlin.“ Dieser Fehler wurde behoben und korrigiert: „Enno Lenze verdient seinen Lebensunterhalt als Verleger in Berlin. Einen Monat nach unserem Interview erhält Enno keinen Zugriff mehr auf seine Internetseiten.“ 